\title{
Management of anticoagulants before and after endoscopy
}

\author{
Axel Hittelet MD, Jacques Devière MD PhD
}

A Hittelet, J Devière. Management of anticoagulants before and after endoscopy. Can J Gastroenterol 2003;17(5):329. 332.

The risk of procedure-related bleeding while taking anticoagulants needs to be weighed against the risk of thromboembolism from discontinuing these drugs. It is not necessary to adjust anticoagulation for low-risk procedures, such as upper endoscopy with biopsy, colonoscopy with biopsy or endoscopic retrograde cholangiopancreatography with stent insertion (but without sphincterotomy). Procedures that incur a high risk of bleeding include polypectomy, endoscopic sphincterotomy, laser therapy, mucosal ablation and treatment of varices. For these procedures, warfarin should be discontinued four to five days beforehand. Depending on the risk of thromboembolism, that is based on the nature of the underlying condition, the patient may require vitamin $\mathrm{K}$ and/or fresh frozen plasma (to ensure that coagulation parameters are within the normal range) or heparin infusions (to ensure that some degree of anticoagulation is maintained). Low molecular weight heparin is an alternative to unfractionated heparin for select cases with a high risk of thromboembolism. Warfarin therapy may generally be resumed on the night of the procedure and may be supplemented by heparin in patients with a high risk of thromboembolism. It is not necessary to discontinue acetylsalicylic acid or nonsteroidal anti-inflammatory drugs, when used in standard doses, for endoscopic procedures. There are insufficient data to make recommendations regarding newer antiplatelet drugs, such as ticlopidine or clopidogrel, but it is prudent to discontinue these medications seven to 10 days before a high-risk procedure.

Key Words: Anticoagulant; Bleeding; Endoscopy; NSAID; Thromboembolism

\section{La prise en charge des anticoagulants avant et après une endoscopie}

RÉSUMÉ : Le risque d'hémorragie découlant d'une intervention lorsque le patient prend des anticoagulants mérite d'être soupesé par rapport au risque de thrombo-embolie pouvant se produire en raison de l'interruption du médicament. Il n'est pas nécessaire de modifier la prise des anticoagulants en cas d'interventions à faible risque, telles qu'une endoscopie avec biopsie, une coloscopie avec biopsie ou une cholangiopancréatographie endoscopique rétrograde avec insertion d'extenseur (mais sans sphinctérotomie). Les interventions qui entraînent un risque élevé de saignements incluent les polypectomies, la sphinctérotomie endoscopique, l'ablation de la muqueuse au laser et le traitement des varices. Dans ces cas, il faut interrompre le traitement à la warfarine de quatre à cinq jours avant l'intervention. Selon le risque de thrombo-embolie, qui dépend de la nature de la maladie sous-jacente, le patient peut avoir besoin de vitamine $\mathrm{K}$, de plasma congelé ou frais (afin de garantir que les paramètres de coagulation sont dans la plage normale) ou d'une infusion d'héparine (afin de garantir le maintien d'un certain degré d'anticoagulation). L'héparine de faible masse moléculaire peut remplacer l'héparine non fractionnée dans des cas précis courant un fort risque de thromboembolie. D'ordinaire, le traitement à la warfarine peut être repris la nuit de l'intervention et complété par de l'héparine chez les patients présentant un fort risque de thrombo-embolie. Il n'est pas nécessaire d'arrêter de prendre de l'acide acétylcalycilique ou des anti-inflammatoires non stéroïdiens, s'ils sont pris à des doses normales, pour pouvoir procéder à l'endoscopie. On ne possède pas assez de données pour faire des recommandations au sujet des nouveaux antiplaquettaires, comme la triclopidine et le clopidrogel, mais il est prudent de cesser de prendre ces médicaments de cinq à dix jours avant une intervention à haut risque.

A nticoagulants and antiplatelet agents are increasingly employed for primary and secondary prophylaxis of cardiovascular and cerebrovascular thromboembolic disease and venous thromboembolism. Therapeutic endoscopy is also evolving and becoming more widely used. The management of anticoagulation during endoscopy is complex, because a wide variety of clinical situations need to be considered. This might explain why the attitudes of physicians on this issue vary greatly (1). One must balance the risk of thromboembolism from withholding the medication with the likelihood of bleeding during and after the procedure. A rational decision can be made only if the risks of thrombosis and bleeding, and the resulting morbidity and mortality, can be quantified.

\section{PROCEDURE RISKS}

Endoscopic techniques can be classified into those with high and low risks for bleeding (Table 1). Low-risk procedures include diagnostic esophagogastroduodenoscopy (EGD), colonoscopy (even with biopsy), endoscopic retrograde cholangiopancreatography (with stent insertion but without sphincterotomy), endosonography (EUS), and push enteroscopy. For example, the risk of bleeding during EGD has been estimated at $0.03 \%(2)$.

High-risk procedures include gastric polypectomy (which has a $4 \%$ risk of bleeding), colonoscopic polypectomy $(0.2 \%$ to $3 \%)$, mucosectomy from the esophagus, stomach or colon, endoscopic sphincterotomy $(2.5 \%$ to $5 \%)$, ampullectomy, tak-

This article was originally presented at the 15th International Course on Therapeutic Endoscopy, hosted by the Wellesley Group, Division of

Gastroenterology, St Michael's Hospital, Toronto, Ontario, October 9-12, 2002

Department of Gastroenterology, Université Libre de Bruxelles, Bruxelles, Belgium

Correspondence and reprints: Dr Jacques Deviere, Department of Gastroenterology, Université Libre de Bruxelles, Hôpital Erasme, Route de

Lennik 808, B-1070 Bruxelles, Belgium. Telephone +32-02-555-3622, fax +32-2-555-4697, e-mail jdeviere@ulb.ac.be 
TABLE 1

Risk of bleeding during endoscopic procedures

\begin{tabular}{ll}
\hline High (greater than 1\%) & Low (less than 1\%) \\
\hline Polypectomy & EGD ( \pm biopsy) \\
gastric (4\%) & Sigmoidoscopy ( \pm biopsy) \\
colonic $(0.2 \%$ to $3 \%)$ & Colonoscopy ( \pm biopsy) \\
Mucosectomy (2\% to $5 \%)$ & ERCP without dilation or \\
Endoscopic sphincterotomy (2\% to 3\%) & sphincterotomy \\
Ampullectomy & Diagnostic EUS \\
Treatment of varices & Enteroscopy \\
PEG* $^{*}$ & Polypectomy with use of a \\
Fine needle aspiration (by EUS) & detachable snare ${ }^{\star}$ \\
Pneumatic dilation* & Esophageal stenting \\
EUS-guided therapy & \\
\hline
\end{tabular}

${ }^{*}$ These procedures may induce bleeding that cannot be controlled endoscopically. This is not proven but could reduce the risk of polypectomy when the polyp is pedunculated. EGD Esophagogastroduodenoscopy; ERCP Endoscopic retrograde cholangiopancreatography; EUS Endoscopic ultrasound; PEG Percutaneous endoscopic gastrostomy; \pm With or without

ing of macrobiopsies, laser mucosal ablation and coagulation (up to 6\%) and the treatment of varices (3-7). In addition, several procedures can induce bleeding that is difficult or impossible to control endoscopically: bougienage or pneumatic dilation of strictures, EUS-guided fine-needle aspiration or therapy, cyst-enterostomy and percutaneous endoscopic gastrostomy.

\section{THROMBOEMBOLISM RISKS}

Several conditions are associated with an increased likelihood of thromboembolism (Table 2). The risks for some of these are well known. On the other hand, anticoagulation regimens for patients with hypercoagulable states and some types of vascular grafts have not been standardized, and decisions should be made on an individual basis.

\section{Arterial thromboembolism}

The most frequent causes of arterial thromboembolism are atrial fibrillation $(\mathrm{AF})$ and valvular heart disease (native or prosthetic). Patients with AF without valvular heart disease have an average incidence of systemic embolism of $4.5 \%$ per year in the absence of antithrombotic therapy (8). The risk is approximately $1 \%$ per year for patients without any other risk factor, $12 \%$ per year for patients with recent cerebral embolism, and as great as $17 \%$ per year in patients older than 75 years of age who have more than one of the following: hypertension, congestive heart failure, past history of thromboembolism, history of cerebrovascular accident or diabetes mellitus $(8,9)$. Other data suggest that the risk of recurrent embolism from any cardiac source is approximately $0.5 \%$ per day during the first month after a stroke (10). Anticoagulation reduces the likelihood of embolism by $66 \%$ in patients with AF without valvular heart disease $(8,9)$. Approximately $20 \%$ of arterial thromboemboli are fatal and $40 \%$ result in permanent disability (8-12).

The average rate of major thromboembolism in patients with mechanical heart valves is $8 \%$ per year without treatment, and is reduced by $75 \%$ by anticoagulant therapy $(13,14)$. The complication rate is less in patients with the newer generation of aortic valve prostheses. In patients with these prostheses, even if the international normalized ratio (INR) is
TABLE 2

Risk of thromboembolism according to the condition for which anticoagulation has been prescribed

Low-risk conditions:
At least three months after deep vein thrombosis
Nonvalvular atrial fibrillation without risk factors
New generation prosthetic heart valve in the aortic position
High-risk conditions:
One to three months after deep vein thrombosis
Atrial fibrillation with some risk factors
First generation prosthetic heart valves (caged-ball or disk valves)
Prosthetic heart valves in two positions
Prosthetic heart valve in mitral position
Prosthetic valves associated with atrial fibrillation
Previous cardiac embolism
Severe left ventricular dysfunction
Very high-risk procedures:
Within one month of deep vein thrombosis
Within one month of acute arterial embolism

subtherapeutic for four to seven days, the risk of thrombosis is only one to two per 1000 patients (15). Therefore, heparin is not necessary in such cases unless the INR is expected to be less than 2.0 for at least five days.

Mechanical heart valves that are associated with a high risk of thrombosis include those that are in the mitral position or in both the mitral and aortic positions, and caged-ball or disk valves of the old generation $(14,16)$. Patients with concomitant AF, prior embolic events or severe left ventricular dysfunction are also at high risk for thrombosis. In these situations, the INR should be monitored daily, and intravenous heparin should be initiated when the INR falls below 2.0 $(16,17)$.

\section{Venous thromboembolism}

The risk of recurrent proximal venous thromboembolism (VTE) after an acute episode is greatest during the first month, and approaches $50 \%$ without anticoagulant therapy (18). The administration of warfarin during this month reduces the risk to roughly $10 \%$, and three months of treatment reduces the risk to $5 \%(19-21)$. A vena cava filter should be considered if a high risk endoscopic procedure is required during the first two weeks after VTE. In patients with a hereditary hypercoagulable state or active cancer, discontinuation of warfarin is reported to be associated with a risk of thromboembolism of $15 \%$ per year (22).

The consequences of VTE are significant. The risk of pulmonary embolism is $6.4 \%$ within the first two weeks after surgery in patients with a history of VTE (23). It has been estimated that $6 \%$ of these episodes are fatal and $2 \%$ result in permanent disability $(19,20,24)$.

Overall, anticoagulation reduces the risk of recurrent VTE by about $80 \%(18,20,24)$. Prophylactic measures that are less likely to cause bleeding than intravenous heparin should be promoted. These include low molecular weight heparin (LMWH), graduated compression stockings, and intermittent pneumatic compression.

Some factors associated with endoscopic procedures may be important but have not been specifically evaluated. Colonoscopy preparation, particularly when administered to 
elderly subjects, can cause intravascular volume depletion $(25,26)$, which may increase the risk of VTE. One should consider intravenous hydration before and during colonoscopy in such patients.

\section{BLEEDING RISKS}

Most bleeding that occurs after an endoscopic procedure is immediate, and results from inadequate hemostasis (27). In more than $80 \%$ of cases of bleeding, the diagnosis is made within $48 \mathrm{~h}$ of the procedure $(28,29)$. Most of the remainder of bleeding episodes occur within the next 10 days.

Some studies have found that severe acute bleeding from peptic ulcer disease can safely be managed endoscopically even in patients who take anticoagulants $(30,31)$. Nevertheless, surgical studies have shown that the restoration of intravenous heparin therapy immediately after surgery increases the absolute rate of major hemorrhage by approximately $3 \%$, and that $3 \%$ of these episodes are fatal or lead to long term disability $(21,32,33)$.

\section{WARFARIN}

After warfarin is discontinued, the INR can be expected to fall to 1.5 in almost all patients within roughly four days if the INR starts at 2.0 to 3.0 , or within five days if the INR starts at 2.5 to 3.5 (34). Once the INR reaches 1.5 , surgical or endoscopic procedures can be performed without an increased risk of bleeding $(34,35)$.

The INR should be measured on the day before endoscopy. If the INR is higher than 1.7, a small dose of vitamin $\mathrm{K}$ (1 mg subcutaneously) should be administered. If the INR is between 1.7 and 2.0 immediately before endoscopy, fresh frozen plasma may be given (21).

After warfarin therapy is resumed, approximately three days are required for the INR to reach 2.0 (36). Therefore, warfarin therapy may be restarted on the night of the procedure provided that there is no obvious bleeding. Although there is biochemical evidence of a hypercoagulable state after cessation of oral anticoagulants (37), the existence of this phenomenon has not yet been confirmed clinically (38).

\section{HEPARIN}

In high-risk patients who undergo high-risk procedures, bridging anticoagulant therapy is required when the INR is less than 2.0. LMWHs are being increasing used, even though there has been no prospective controlled study of their safety and effectiveness for gastrointestinal procedures. They are associated with lower risks of bleeding than that with conventional (unfractionated) heparin, at doses that provide equivalent antithrombotic effects (39). Because their dose-response relationships are more predictable, LMWHs are given in fixed doses without laboratory monitoring, which reduces the perioperative hospitalization and related costs $(40,41)$. They should not be used, however, in cases of renal insufficiency.

\section{ANTIPLATELET DRUGS}

Although published data are limited, it has been stated that, when used in standard doses, acetylsalicylic acid and nonsteroidal anti-inflammatory drugs do not increase the risk of significant bleeding after EGD with biopsy, colonoscopy with biopsy, polypectomy or biliary sphincterotomy $(5,42)$.
The thienopyridine, platelet adenosine diphosphate-receptor blocker, such as ticlopidine and clopidogrel, are less likely than acetylsalicylic acid to cause gastrointestinal and other bleeding, although the risk is not zero (43-45). Seven days are required for the total pool of functioning platelets to be restored when these drugs are used, which is an important consideration when treating patients who are at a high risk of bleeding.

Some authorities recommend that antiplatelet drugs be withdrawn for seven to 10 days before liver biopsy (46). This recommendation may be extrapolated to endoscopic procedures that could induce bleeding that is endoscopically intractable, such as pneumatic dilation of benign or malignant strictures, EUS-guided fine-needle aspiration and percutaneous endoscopic gastrostomy.

\section{Low-risk procedures}

\section{RECOMMENDATIONS}

No adjustment in anticoagulation is required for low-risk procedures, regardless of the underlying condition. Elective procedures should be avoided, however, when the INR is above the therapeutic range.

High-risk procedures in patients with low-risk conditions In these situations, warfarin should be discontinued four to five days before the scheduled procedure, and the INR should be measured on the day before the procedure. If the INR is greater than $1.5,1 \mathrm{mg}$ of vitamin $\mathrm{K}$ should be given subcutaneously. Fresh frozen plasma can be given immediately before the procedure, if necessary, to reduce the INR to 1.5 . A prophylactic dose of LWMH could be used as an alternative treatment in select cases.

High-risk procedures in patients with high-risk conditions In these situations, warfarin should be discontinued four to five days before the procedure. The decision to administer intravenous heparin, once the INR falls below the therapeutic range (ie, INR less than 2.0), should be made on an individual basis. Therapeutic doses of LMWH could be used as an alternative to heparin in selected cases.

\section{High-risk procedures in patients with very high-risk conditions}

If the procedure cannot be delayed, warfarin therapy should be discontinued four to five days before the procedure, and a heparin infusion should be administered as soon as the INR falls below 2.0. Heparin should be stopped $6 \mathrm{~h}$ before the procedure and restarted within 2 to $12 \mathrm{~h}$ after the procedure, in the absence of clinical bleeding. Warfarin therapy can generally be resumed on the night of the procedure. Heparin and warfarin should be given together until the INR has reached the target therapeutic range, usually within two or three days.

\section{Drugs affecting platelet function}

In the absence of a pre-existing bleeding disorder, endoscopic procedures may be performed on patients who take acetylsalicylic acid or nonsteroidal anti-inflammatory drugs in standard doses. The data on other drugs that affect platelet function, such as ticlopidine or clopidogrel, are inadequate to make a recommendation. Nevertheless, for a high-risk procedure, the medication probably should be discontinued seven to 10 days beforehand. 


\section{REFERENCES}

1. Kadakia SC, Angueira CE, Ward JA, Moore M. Gastrointestinal endoscopy in patients taking antiplatelet agents and anticoagulants Survey of ASGE members. American Society for Gastrointestinal Endoscopy. Gastrointest Endosc 1996;44:309-16.

2. Newcomer MK, Brazer SR. Complications of upper gastrointestinal endoscopy and their management. Gastrointest Endosc Clin North Am 1994:4:551-70.

3. ReMine SG, Hughes RW Jr, Weiland LH. Endoscopic gastric polypectomies. Mayo Clin Proc 1981;56:371-5.

4. Vernava AM 3rd, Longo WE. Complications of endoscopic polypectomy. Surg Oncol Clin N Amer 1996;5:663-73.

5. Cotton PB, Lehman G, Vennes J, et al. Endoscopic sphincterotomy complications and their management: An attempt at consensus. Gastrointest Endosc 1991;37:383-93.

6. Mathus-Vliegen EM, Tytgat GN. Nd:YAG laser photocoagulation in colorectal adenoma. Evaluation of its safety, usefulness, and efficacy. Gastroenterology 1986;90:1865-73.

7. Rutgeerts P, Vantrappen G, Broeckaert L, et al. Palliative Nd:YAG laser therapy for cancer of the esophagus and gastroesophageal junction: impact on the quality of remaining life. Gastrointest Endosc 1988;34:87-90.

8. Risk factors for stroke and efficacy of antithrombotic therapy in atrial fibrillation. Analysis of pooled data from five randomized controlled trials. Arch Intern Med 1994;154:1449-57.

9. EAFT (European Atrial Fibrillation Trial) Study Group. Secondary prevention in non-rheumatic atrial fibrillation after transient ischaemic attack or minor stroke. Lancet 1993;342:1255-62.

10. Cerebral Embolism Task Force. Cardiogenic brain embolism. Arch Neurol 1986;43:71-84.

11. Caplan LR, Hier DB, D'Cruz I. Cerebral embolism in the Michael Reese Stroke Registry. Stroke 1983;14:530-6.

12. Anderson CS, Jamrozik KD, Broadhurst RJ, Stewart-Wynne EG. Predicting survival for 1 year among different subtypes of stroke. Results from the Perth Community Stroke Study. Stroke 1994;25:1935-44.

13. Mok CK, Boey J, Wang R, et al. Warfarin versus dipyridamoleaspirin and pentoxifylline-aspirin for the prevention of prosthetic heart valve thromboembolism: a prospective randomized clinical trial. Circulation 1985;72:1059-63.

14. Cannegieter SC, Rosendaal FR, Briet E. Thromboembolic and bleeding complications in patients with mechanical heart valve prostheses. Circulation 1994;89:635-41.

15. American Society for Gastrointestinal Endoscopy. Guideline on the management of anticoagulation and antiplatelet therapy for endoscopic procedures. Gastrointest Endosc 1998;48:672-5.

16. Tiede DJ, Nishimura RA, Gastineau DA, Mullany CJ, Orszulak TA, Schaff HV. Modern management of prosthetic valve anticoagulation. Mayo Clin Proc 1998;73:665-80.

17. Katholi RE, Nolan SP, McGuire LB. Living with prosthetic heart valves. Subsequent noncardiac operations and the risk of thromboembolism or hemorrhage. Am Heart J 1976;92:162-7.

18. Hull R, Delmore T, Genton E, et al. Warfarin sodium versus lowdose heparin in the long-term treatment of venous thrombosis. N Engl J Med 1979;301:855-8.

19. Research Committee of the British Thoracic Society. Optimum duration of anticoagulation for deep-vein thrombosis and pulmonary embolism. Lancet 1992;340:873-6.

20. Levine MN, Hirsh J, Gent M, et al. Optimal duration of oral anticoagulant therapy: a randomized trial comparing four weeks with three months of warfarin in patients with proximal deep vein thrombosis. Thromb Haemostasis 1995;74:606-11.

21. Kearon C, Hirsh J. Management of anticoagulation before and after elective surgery. N Engl J Med 1997;336:1506-11.

22. Hull RD, Carter CJ, Jay RM, et al. The diagnosis of acute, recurrent, deep-vein thrombosis: A diagnostic challenge. Circulation 1983;67:901-6.

23. Clagett GP, Reisch JS. Prevention of venous thromboembolism in general surgical patients. Results of meta-analysis. Ann Surg 1988;208:227-40.

24. Schulman S, Rhedin AS, Lindmarker P, et al. A comparison of six weeks with six months of oral anticoagulant therapy after a first episode of venous thromboembolism. Duration of Anticoagulation Trial Study Group. N Engl J Med 1995;332:1661-5.

25. Hanning CD. Bowel preparation at home in elderly people. Give a simultaneous infusion of saline in frail patients. Br Med J 1997;314:74. (Lett)

26. Lieberman DA, Ghormley J, Flora K. Effect of oral sodium phosphate colon preparation on serum electrolytes in patients with normal serum creatinine. Gastrointest Endosc 1996;43:467-9.

27. Waye JD, Kahn O, Auerbach ME. Complications of colonoscopy and flexible sigmoidoscopy. Gastrointest Endosc Clin North Am 1996;6:343-77.

28. Rabenstein T, Schneider HT, Bulling D, et al. Analysis of the risk factors associated with endoscopic sphincterotomy techniques: preliminary results of a prospective study, with emphasis on the reduced risk of acute pancreatitis with low-dose anticoagulation treatment. Endoscopy 2000;32:10-9.

29. Oren A, Breumelhof R, Timmer R, Biesma DH, Hoekstra JB. Abnormal clotting parameters before therapeutic ERCP: do they predict major bleeding? Eur J Gastroenterol Hepatol 1999;11:1093-7.

30. Choudari CP, Rajgopal C, Palmer KR. Acute gastrointestinal haemorrhage in anticoagulated patients: diagnoses and response to endoscopic treatment. Gut 1994;35:464-6.

31. Vreeburg EM, de Bruijne HW, Snel P, Bartelsman JW, Rauws EA, Tytgat GN. Previous use of non-steroidal anti-inflammatory drugs and anticoagulants: the influence on clinical outcome of bleeding gastroduodenal ulcers. Eur J Gastroenterol Hepatol 1997;9:41-4.

32. Collins R, Scrimgeour A, Yusuf S, Peto R. Reduction in fatal pulmonary embolism and venous thrombosis by perioperative administration of subcutaneous heparin. Overview of results of randomized trials in general, orthopedic, and urologic surgery. N Engl J Med 1988;318:1162-73.

33. Kakkar VV, Cohen AT, Edmonson RA, et al. Low molecular weight versus standard heparin for prevention of venous thromboembolism after major abdominal surgery. The Thromboprophylaxis Collaborative Group. Lancet 1993;341:259-65.

34. White RH, McKittrick T, Hutchinson R, Twitchell J. Temporary discontinuation of warfarin therapy: changes in the international normalized ratio. Ann Intern Med 1995;122:40-2.

35. Francis CW, Marder VJ, Evarts CM, Yaukoolbodi S. Two-step warfarin therapy. Prevention of postoperative venous thrombosis without excessive bleeding. JAMA 1983;249:374-8.

36. Harrison L, Johnston M, Massicotte MP, Crowther M, Moffat K, Hirsh J. Comparison of 5-mg and 10-mg loading doses in initiation of warfarin therapy. Ann Intern Med 1997;126:133-6.

37. Palareti G, Legnani C, Guazzaloca, et al. Activation of blood coagulation after abrupt or stepwise withdrawal of oral anticoagulants a prospective study. Thromb Haemostasis 1994;72:222-6.

38. Palareti G, Legnani C. Warfarin withdrawal. Pharmacokineticpharmacodynamic considerations. Clin Pharmacokinet 1996;30:300-13

39. Ginsberg JS. Management of venous thromboembolism. N Engl J Med 1996;335:1816-28.

40. Goldstein JL, Larson LR, Yamashita BD, Fain JM, Schumock GT. Low molecular weight heparin versus unfractionated heparin in the colonoscopy peri-procedure period: a cost modeling study. Am J Gastroenterol 2001;96:2360-6.

41. Spandorfer JM, Lynch S, Weitz HH, Fertel S, Merli GJ. Use of enoxaparin for the chronically anticoagulated patient before and after procedures. Am J Cardiol 1999;84:478-80.

42. Freeman ML, Nelson DB, Sherman S, et al. Complications of endoscopic biliary sphincterotomy. N Engl J Med 1996;335:909-18.

43. Desager JP. Clinical pharmacokinetics of ticlopidine. Clin Pharmacokinet 1994;26:347-55.

44. Boysen G. Bleeding complications in secondary stroke prevention by antiplatelet therapy: a benefit-risk analysis. I Intern Med $1999 ; 246: 239-45$

45. Jarvis B, Simpson K. Clopidogrel: a review of its use in the prevention of atherothrombosis. Drugs 2000;60:347-77.

46. Bravo AA, Sheth SG, Chopra S. Liver biopsy. N Engl J Med 2001;344:495-500. 


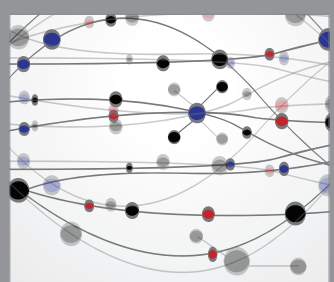

The Scientific World Journal
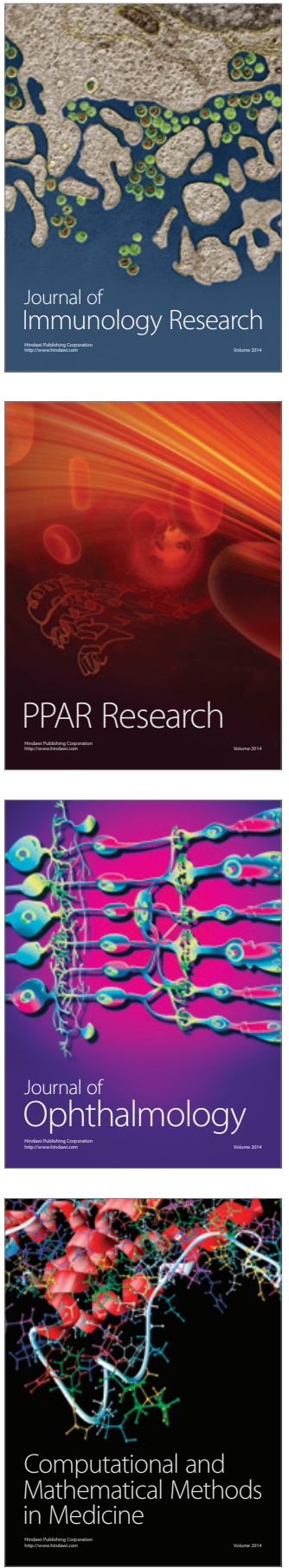

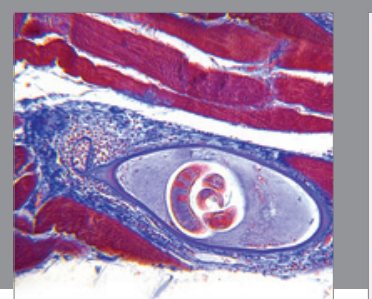

Gastroenterology Research and Practice

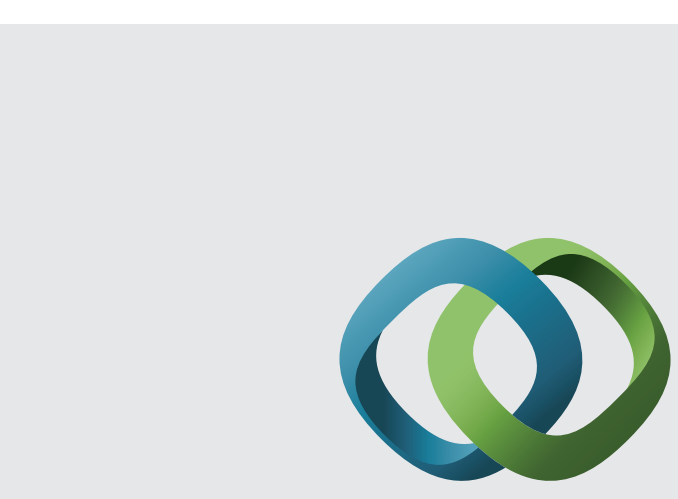

\section{Hindawi}

Submit your manuscripts at

http://www.hindawi.com
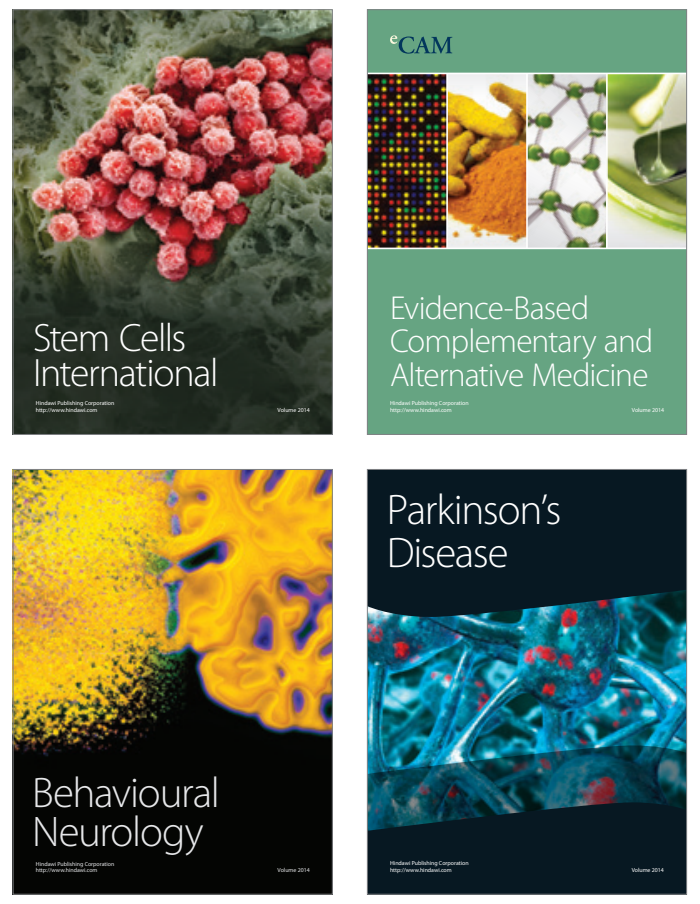
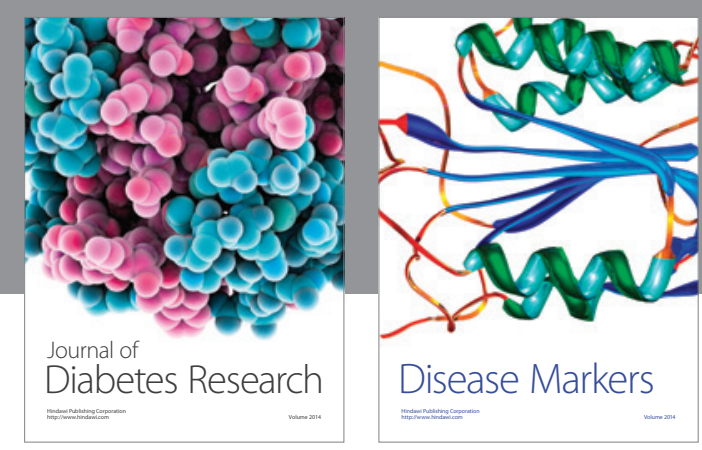

Disease Markers
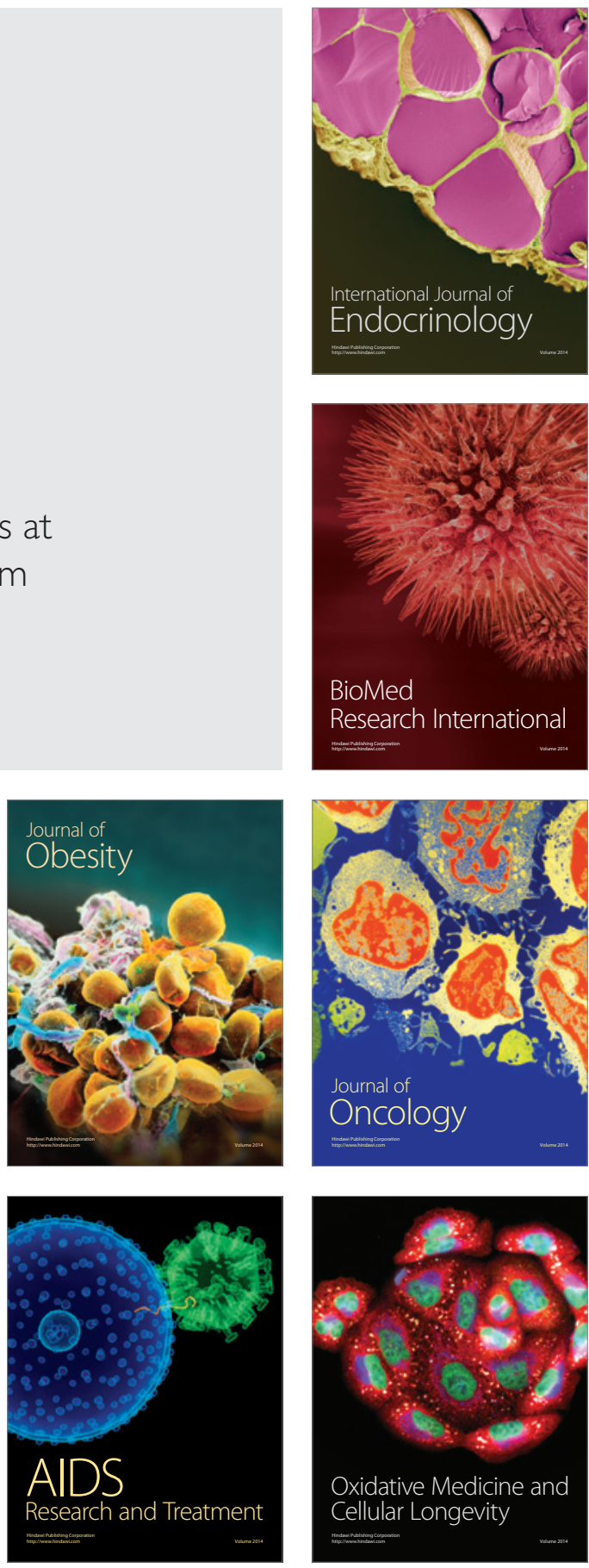